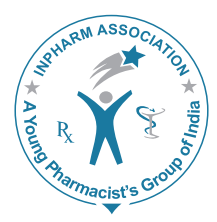

\title{
Molecular docking and preclinical studies of Gymnema sylvestre on endothelial nitric oxide synthase in Type-2 diabetes-related complications
}

\author{
K. Abedulla Khan ${ }^{1 *}$, Shabnam Dobani², Mohammed Adil Shareef ${ }^{2}$ \\ ${ }^{1}$ Department of Pharmacy Practice, Sultan Ul Uloom College of Pharmacy, Hyderabad, Andhra Pradesh, \\ India, ${ }^{2}$ Department of Pharmaceutical Chemistry, Sultan Ul Uloom College of Pharmacy, Hyderabad, \\ Andhra Pradesh, India
}

\begin{abstract}
Aim: The purpose of the study was to investigate the effect of different compounds from leaves of Gymnema sylvestre (GS) on nitric oxide (NO) production. Materials and Methods: To study the binding and effect of different compounds from GS 10 molecules were docked on the enzyme endothelial NO synthase (eNOS) using molegro virtual docker and the result was compared with that of the agonists (acetylcholine, bradykinin, and serotonin). Further to confirm the activity animal studies were done on albino rats blood glucose levels were measured using glucometer and NO levels were estimated spectrophotometrically using griess agent. Results: Docking studies showed that almost all the compounds from the leaves of GS bind perfectly with eNOS with the lowest binding energies similar to that of the agonists. Animal studies confirmed the docking results when blood glucose levels decreased and NO levels increased in diabetic rats treated with GS leaf extract. Conclusion: Docking and animal studies show that leaf extract of GS might help in improving the production of NO by stimulating eNOS and thus, can be used as an agent to avoid diabetes and diabetic vascular complications.
\end{abstract}

Key words: Endothelial nitric oxide synthase, diabetes and diabetic vascular complications, Gymnema sylvestsre, molecular docking

\section{INTRODUCTION}

Diabetes mellitus refers to the group of diseases that lead to high blood glucose levels due to defects in either insulin

\begin{tabular}{|c|c|}
\hline \multicolumn{2}{|c|}{ Access this article online } \\
\hline Journal Sponsor & \multirow[b]{2}{*}{$\begin{array}{l}\text { Website: } \\
\text { www.jyoungpharm.org }\end{array}$} \\
\hline \multirow{2}{*}{ www.phcog net } & \\
\hline & $\begin{array}{l}\text { DOI: } \\
\text { 10.5530/jyp.2014.4.5 }\end{array}$ \\
\hline
\end{tabular}

secretion or insulin action. ${ }^{1}$ The most common and lifethreatening disorders that besets Type 2 diabetic individuals are vascular complications like atherosclerosis, retinopathy, nephropathy, etc.

Nitric oxide (NO) is normally produced from L-arginine by endothelial NO synthase (eNOS) in the vasculature. ${ }^{2}$ Decreased production of NO by eNOS due to glucose overload is a major reason for diabetic vascular complications. Molecular docking is used in the study to predict the binding orientation of molecules from Gymnema sylvestre (GS) to their protein target on eNOS to predict the

*Address for correspondence:

Dr. K. Abedulla Khan, Sultan Ul Uloom College of Pharmacy, Banjara Hills, Road No. 3, Hyderabad - 500 034, Andhra Pradesh, India.

Phone: 91-9948063270,Tel.: 00914023280222,E-mail: abidulla.k@gmail.com 
affinity and activity of the molecule since docking plays an important role in the rational design of drugs.

GS is a large woody climber plant, from the asclepiadaceae family, and is native to central and western India, tropical Africa and Australia. This plant has been used in ayurvedic medicine for the treatment of diabetes in India for centuries. Gymnemic acids are very commonly used in diabetic and also used in inflammation. ${ }^{17}$ The anti-diabetic class of molecules has been identified as a group of closely related gymnemic acids. ${ }^{3,4}$

Docking is frequently used to predict the binding orientation of small molecule drug candidates to their protein targets in order to predict the affinity and activity of the tiny molecule. Hence, docking plays a vital role in the rationale. ${ }^{5}$

The intention of the present study was to find out the effect of different compounds from leaves of GS on NO production by molecular modeling and to confirm these results by animal studies.

\section{MATERIALS AND METHODS}

\section{Materials}

The leaves of GS were collected from Osmania University botanical garden of Hyderabad, India. Meshrangi (standard GS) was obtained from Himalaya Drug Company, Bangalore, India. Alloxan monohydrate and all the other chemicals were acquired from S. D. Fine Chemicals Ltd., Mumbai, India.

\section{Preparation of aqueous extract}

The plant leaves were air-dried under shed at $25^{\circ} \mathrm{C}$, and the dried leaves were made into a fine powder with an auto-mix blender. The powder was kept in the deep freezer until the time of use.

One hundred grams of dry fine powder was suspended in $250 \mathrm{~mL}$ of water for $2 \mathrm{~h}$ and then boiled at $60-65^{\circ} \mathrm{C}$ for $30 \mathrm{~min}$ (since boiled decoction of the leaf of this plant has been used as remedy for diabetes). ${ }^{6}$ The collected extract was pooled and passed through a fine cotton cloth. The filtrate upon evaporation at $40^{\circ} \mathrm{C}$ yielded $20 \%$ semi-solid extract. ${ }^{7}$

\section{Docking requirements}

Docking here has been performed using molegro virtual docker (MVD). MVD is an integrated environment for studying and predicting how ligands interact with Macromolecules.

The 3D structure of the protein was obtained from protein data bank. The sequence view of the two chains A and B were obtained from MVD - sequence viewer. Ten compounds (gymnemic acid; gymnmema saponins (I-V); gymnemagenin; gymnemosides (a and b); deacylgymnemic acid $)^{8}$ from the leaves of GS were docked on eNOS. The structures of ligands, agonists, and compounds from gumnema were obtained from chem spider (chemical database).

\section{Maintenance of animals}

All the animal studies were conducted as per the guidelines of Institutional Animal Ethics Committee (IAEC) and protocol was approved (Reg. No: IAEC/SUCP/03/212). 18 albino rats weighing 150-250 g were housed individually in cages with free access to water and food throughout the experimental period. The standard laboratory conditions of light and temperature at $25-27^{\circ} \mathrm{C}$ and $55 \%$ relative humidity are maintained. The animals were randomly divided into control and diabetic groups.

\section{Experimental groups}

Eighteen rats selected from an inbred colony were divided into three groups, six rats in each group. Alloxan was injected to two groups (Group II and Group III) of rats at dosage of $100 \mathrm{mg} / \mathrm{kg}$ and again after 2 days $150 \mathrm{mg} / \mathrm{kg}$ body weight except for the Group I.

Group I: Rats of this group did not receive alloxan but were given gymnema extract every day $400 \mathrm{mg} / \mathrm{kg}$ body weight orally until 60 days.

Group II: Rats were induced diabetes with alloxan $100 \mathrm{mg} / \mathrm{kg}$ body weight and again after 2 days alloxan $150 \mathrm{mg} / \mathrm{kg}$ body weight was administered.

Group III: (alloxan + GS): Rat was induced diabetes with alloxan $(100 \mathrm{mg} / \mathrm{kg}$ and again after 2 days $150 \mathrm{mg} / \mathrm{kg}$ body weight I.P) and then treated with GS leaf extract $400 \mathrm{mg} / \mathrm{kg}$ body weight every day until 60 days.

\section{Experimental induction of diabetes}

The rats were injected intraperitoneally with alloxan monohydrate dissolved in sterile normal saline at a dose of $100 \mathrm{mg} / \mathrm{kg}$ body weight and then again after 2 days, they were administered with alloxan $150 \mathrm{mg} / \mathrm{kg}$ body weight. Blood samples collected before the administration of alloxan and after 4 days of alloxan administration. Diabetic

Journal of Young Pharmacists Vol 6 • Issue 4 • Oct-Dec 2014 
state was confirmed when the blood sugar level was above $250 \mathrm{mg} / \mathrm{dl}$. The rats with moderate diabetes were used in experiment. ${ }^{7,9}$

\section{Drug administration and estimation of glucose}

The aqueous leaf extract was administered orally through intra-gastric tube at the dose of $400 \mathrm{mg} / \mathrm{kg}$ body weight. ${ }^{10}$ For estimation of glucose, we have chosen glucometer "one touch select simple." In this glucometer, blood glucose estimated quantitatively.

\section{Estimation of NO levels}

NO was estimated by Griess reagent. The method involves the use of the Griess diazotization reaction to spectrophotometrically detect nitrite formed by the spontaneous oxidation of NO under physiological conditions. ${ }^{11}$

\section{Statistical analysis}

Data and statistical analysis data were shown as mean \pm standard error of the mean. The significance was determined by applying student's $t$-test. $P<0.05$ were considered significant.

\section{RESULTS}

\section{Molecular docking of compounds from leaves of GS on eNOS}

To study the effect of gymnema extract on enzyme eNOS, molecular docking was performed. Ten compounds from the leaves of GS (gymnemic acid, gymnema saponins I-V, gymnemagenin, gymnemosides A and B, deacylgymnemic acid $^{12-16}$ were docked on the enzyme. It was observed that the binding energies for all the compounds were very low which show that every compound has a good affinity for the enzyme eNOS.

The binding energies of these compounds were compared to the agonist acetylcholine, bradykinin, and serotonin. Almost all the compounds bind to eNOS at the similar site as that of the agonist. Of all, gymnema saponin $\mathrm{V}$ shows the best binding energy with the energy value -44.3324 at Trp447 followed by gymnemic acid with the energy value -42.501 at Trp445 (Figures $1 \& 2$ ). These results prove that gymnema saponin and gymnemic acid might exert agonistic activity better than Bradykinin and acetylcholine which binds at $\operatorname{Trp} 447$ (-37.4521) and $\operatorname{Trp} 445$ (-9.78165), respectively (Figure 3).
Gymnema saponin II, gymnema saponin IV, and gymnemoside B bind at the site Phe 460 with binding energies $-11.1702,-14.1258$ and -13.77 , respectively, similar to the agonist serotonin which binds at the same site (Phe460: -19.1536) (Table 1).

Deacylgymnemic acid, gymnemoside a, gymnemagenin, gymnema saponin III, and gymnemasaponin I also show good binding energies similar or greater than the agonists. The above results show that all the compounds from the leaves of GS might act as an agonist of eNOS. The best pose selected shows the following interactions and targets (Figure 4).

Docking was performed for gymnemic acid with the prepared protein, and the following results were obtained. The best pose selected shows the following interactions and targets.

After docking all the structures including agonists, it was observed that all of them bind perfectly with the protein eNOS by showing minimal binding energies. Most of the compounds bind to the protein eNOS at the binding site Trp 445 and Trp 447 with least binding energy similar to that of the agonists which bind to the protein at the same binding site (i.e., Trp 445 and $\operatorname{Trp}$ 447). Furthermore, it is observed that gymnemoside B, gymnema saponin IV, and gymnema saponin II bind at Phe 460 site with least binding energy similar to the agonist serotonin which also binds the protein at Phe 460 with least binding energy.

Table 1: Compounds with their predicted binding energies and targets to eNOS

\begin{tabular}{lcc}
\hline Compound & Target/binding site & Total Binding energy \\
\hline Acetylcholine & Trp 445 & -9.78165 \\
Bradykinin & Trp 445 & -13.4716 \\
& Trp 447 & -37.4521 \\
Serotonin & Trp 445 & -15.1557 \\
& Trp 447 & -16.875 \\
Gymnemic acid & Phe 460 & -19.1536 \\
Gymnemasaponin I & Trp 445 & -42.504 \\
Gymnemasaponin II & Trp 447 & -20.0937 \\
& Trp 445 & -8.50207 \\
Gymnemasaponin III & Phe 460 & -11.1702 \\
Gymnemasaponin IV & Trp 445 & -20.5894 \\
Gymnemasaponin V & Phe 460 & -14.1258 \\
& Trp 445 & -10.6002 \\
Gymnemagenin & Trp 447 & -44.3324 \\
Gymnemoside A & Trp 445 & -8.791 \\
& Trp 445 & -8.49268 \\
Gymnemoside B & Trp 447 & -33.8687 \\
Deacylgymnemic acid & Phe 460 & -13.77 \\
& Trp 445 & -4.66734 \\
\hline & Trp 445 & -12.8219 \\
\hline
\end{tabular}



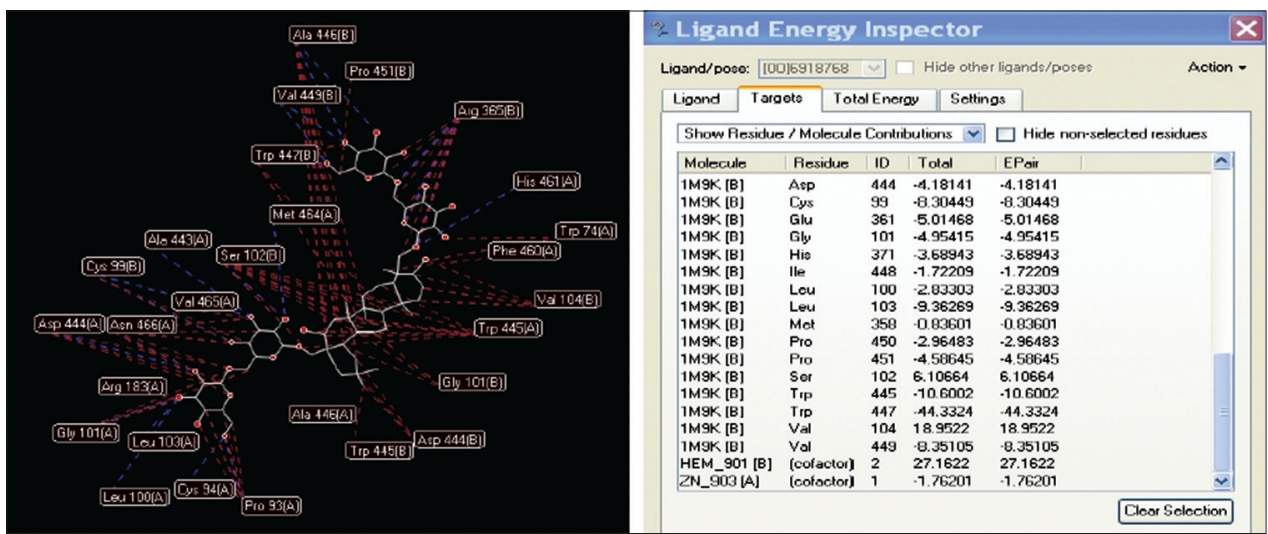

Figure 1: Targets and energy values after docking gymnema saponin $\mathrm{V}$ on endothelial nitric oxide synthase

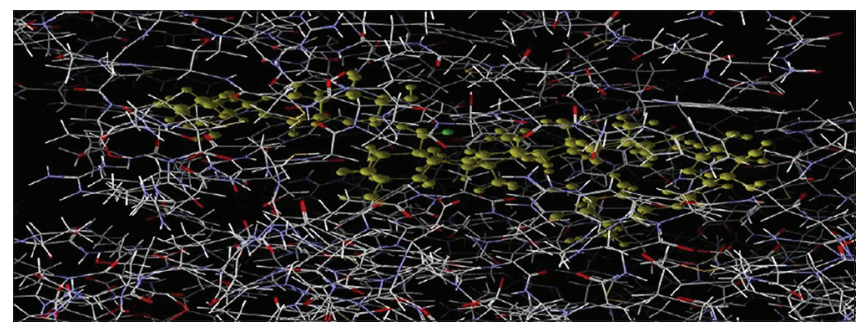

Figure 2: Gymnema saponin V docked into endothelial nitric oxide synthase

Aqueous extract of GS shows the presence of sterols, saponin, triterpenoid, sugars, and tannins. Proteins, amino acids, and alkaloids are not present in the extract. The outcome exhibits the presence of different compounds in the aqueous leaf extract of GS similar to that of the standard marketed preparation.

In Group II and III, an increase in blood glucose levels was observed after alloxan administration (Figure 5). GS extract was given at a dose of $400 \mathrm{mg} / \mathrm{kg}$ body weight once every day till 2 months, and blood glucose levels were monitored on $1^{\text {st }}, 20^{\text {th }}, 40^{\text {th }}$, and $60^{\text {th }}$ day.

In Group I, which received gymnema extract but not alloxan a decrease in blood glucose levels was observed. Whereas a constant increase in blood glucose levels was observed in diabetic control Group II, which did not receive the extract. In the treatment Group III blood glucose levels decreased significantly. Students $t$-test was done, and it was observed that decrease in blood glucose levels in Group I is slightly statistically significant $(P=0.045)$. But in Group III, which had diabetes the decrease in blood glucose levels by GS extract was found to be extremely statistically significant $(P=0.001)^{*}($ Tables $2 \& 3)$.

The above result shows that GS extract effectively lowers the blood glucose levels in diabetic subjects and thus can be used as a glucose-lowering agent in diabetics (Figures 6 and 7).
Table 2: Blood glucose values pre and post alloxan administration

\begin{tabular}{lcc}
\hline Groups & \multicolumn{2}{c}{ Mean \pm SEM $(\mathbf{m g} / \mathrm{dl})$} \\
\cline { 2 - 3 } & Before diabetes induction & After induction with alloxan \\
\hline II & $87.67 \pm 04.33$ & $384.33 \pm 21.21$ \\
III & $93.33 \pm 05.08$ & $393.00 \pm 22.83$ \\
\hline
\end{tabular}

SEM: Standard error of the mean

\section{Estimation of NO}

NO levels were measured for all the groups before and after alloxan administration and after administration of GS extract. The level of NO for each sample was obtained by comparing the absorbance values from the standard calibration graph. A standard curve was obtained from standard nitrite solution $(1-50 \mu \mathrm{m} / \mathrm{l})$ by measuring the absorbance value at $548 \mathrm{~nm}$ (Figure 8).

In Group I was not administered with alloxan. In Group II and III, the levels of NO decreased when alloxan was administered. This shows that in diabetes the levels of $\mathrm{NO}$ decrease (Figure 9). This might be due to the impairment of NO synthase eNOS pathway by glucose overload (Table 4). When GS extract was administered in diabetic rats with decreased NO levels, it was observed that the levels increased slowly (Figures $10 \& 11$ ).

In Group I, GS extract increased NO levels but to a very less extent whereas in Group III, the increase in NO levels was very high. Student's $t$-test also shows that in Group I, the increase in NO levels was not statistically significant $(P=0.2849)$ but in Group III, the increase was very statistically significant $(0.0027) *$. GS extract not only helped in increasing NO levels in treated groups (Group III) but also helped attain normal NO values as were in control (Group I) (Table 5).

The above data show that GS extract might help in increasing NO levels in diabetic patients and can help avoid diabetic vascular complications that occur as a result of 
Table 3: Blood mean glucose levels (mg/dl) after administration of GS extract

\begin{tabular}{lccccc}
\hline Groups & \multicolumn{5}{c}{ Mean \pm SEM } \\
\cline { 2 - 6 } & $\mathbf{1}^{\text {st }}$ day & $\mathbf{2 0}^{\text {th }}$ day & $\mathbf{4 0}^{\text {th }}$ day & $\mathbf{6 0}^{\text {th }}$ day & Percentage changes in blood glucose \\
\hline I & $85.83 \pm 03.97$ & $79.66 \pm 03.61$ & $71.50 \pm 03.13$ & $62.83 \pm 03.03$ & $26.73 \pm 01.58$ \\
II & $381.00 \pm 18.88$ & $407.00 \pm 22.28$ & $440.50 \pm 19.56$ & $463.50 \pm 17.96$ & $22.07 \pm 04.20$ \\
III & $372.50 \pm 21.93$ & $326.83 \pm 15.80$ & $240.00 \pm 12.25$ & $168.33 \pm 07.32^{* * *}$ & $54.59 \pm 00.89$ \\
\hline
\end{tabular}

${ }^{* * *}$ Significant at $P<0.001,{ }^{* *}$ Significant at $P<0.01$, ${ }^{*}$ Significant at $P<0.05$, GS: Gymnema sylvestsre, SEM: Standard error of the mean

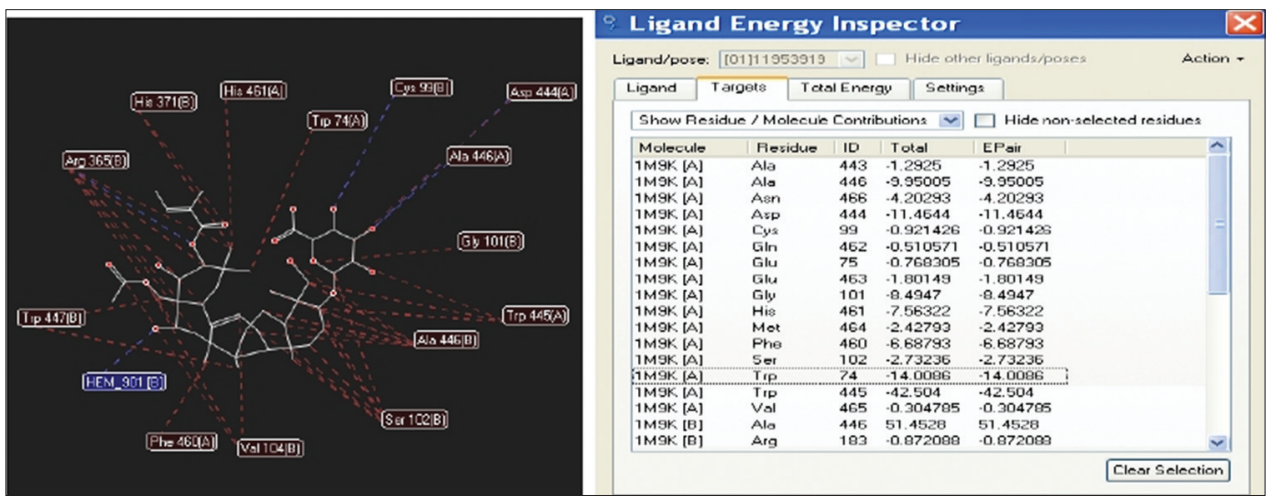

Figure 3: Targets and energy values after docking gymnemic acid on endothelial nitric oxide synthase

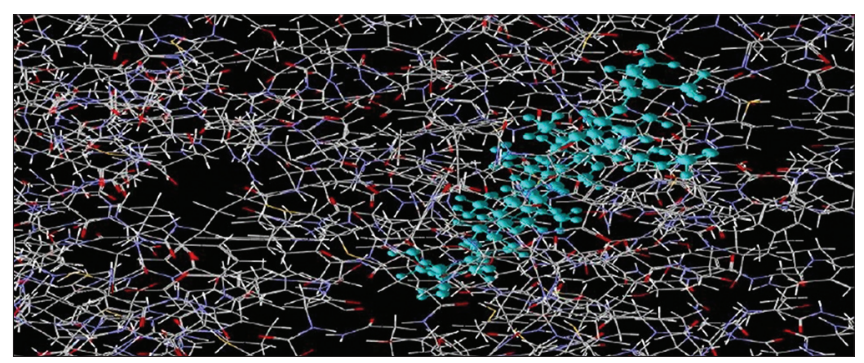

Figure 4: Gymnemic acid docked into endothelial nitric oxide synthase

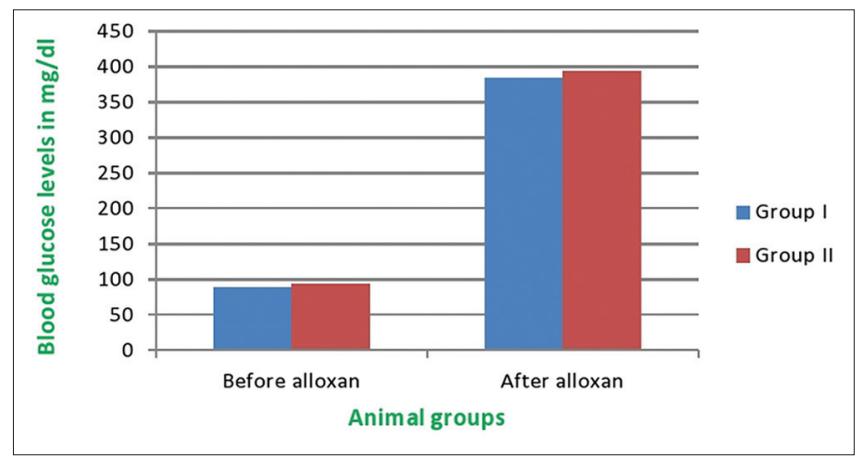

Figure 5: Blood glucose values pre and post alloxan injection

decreased NO levels due to glucose overload and oxidative stress.

The binding energies of these compounds were compared to the agonists such as acetylcholine, bradykinin, and serotonin. Almost all the compounds bind to eNOS at the similar site as that of the agonist. Of all, gymnema saponin $\mathrm{V}$ shows the best binding energy with the energy value -44.3324 at Trp447 followed by gymnemic acid with the energy value -42.501 at Trp445. These results prove that gymnema

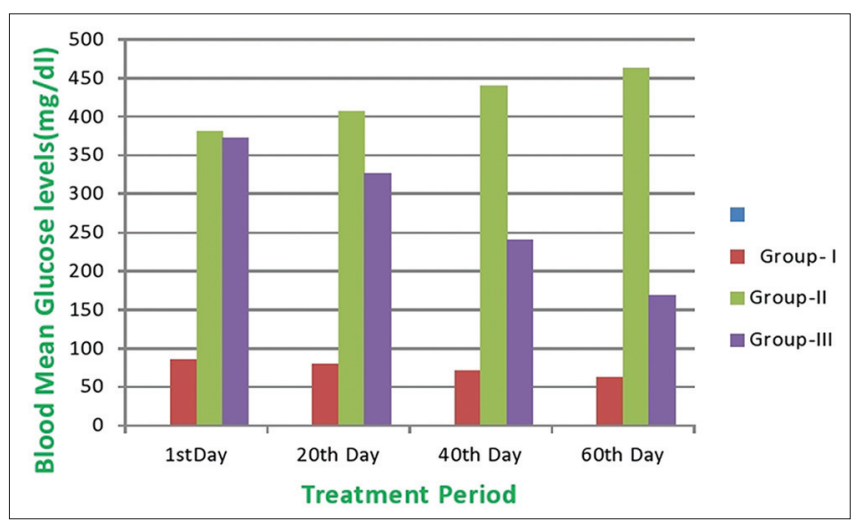

Figure 6: Blood glucose levels after Gymnema sylvestsre administration

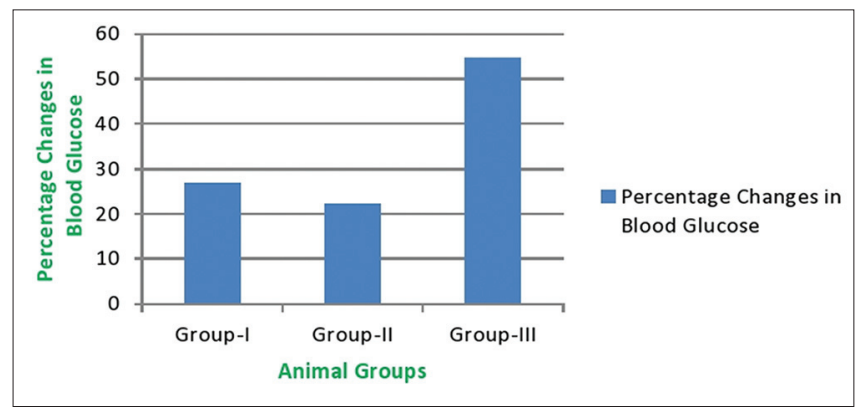

Figure 7: Percentage change in blood glucose levels after Gymnema sylvestsre administration

saponin and gymnemic acid might exert agonistic activity better than Bradykinin and acetylcholine which binds at Trp447 (-37.4521) and Trp445 (-9.78165), respectively.

Gymnema saponin II, gymnema saponin IV, and gymnemoside B bind at the site Phe460 with binding 


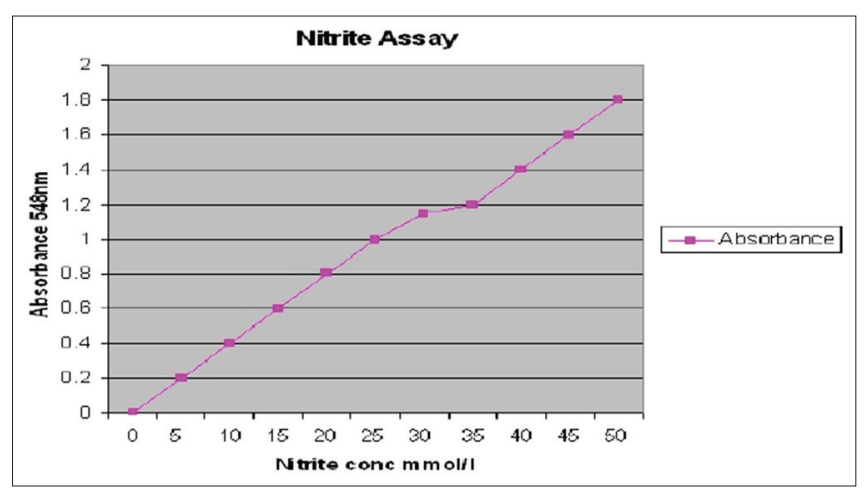

Figure 8: Standard calibration curve for nitrite assay

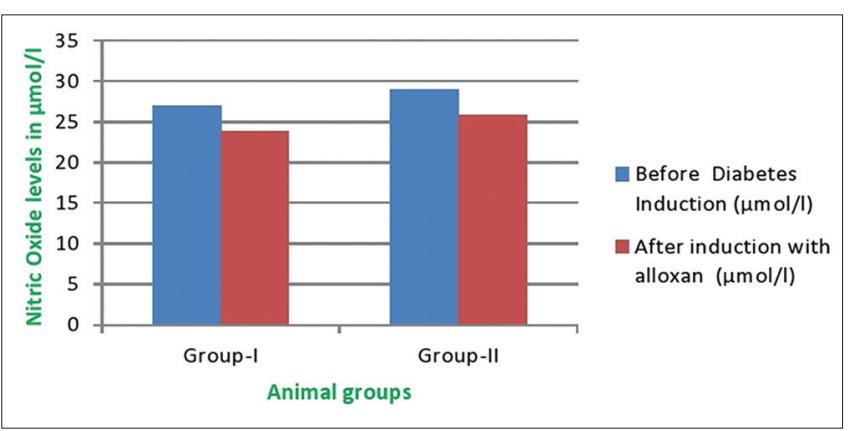

Figure 9: Nitric oxide levels before and after alloxan administration

Table 4: NO levels before and after alloxan administration

\begin{tabular}{lcc}
\hline Groups & $\begin{array}{c}\text { Before diabetes } \\
\text { induction }(\mu \mathrm{mol} / \mathrm{L})\end{array}$ & $\begin{array}{c}\text { After induction with } \\
\text { alloxan }(\mu \mathrm{mol} / \mathrm{L})\end{array}$ \\
\hline II & $26.90 \pm 04.65$ & $23.81 \pm 04.07$ \\
III & $29.00 \pm 04.08$ & $25.89 \pm 03.93$ \\
\hline NO: Nitric oxide & &
\end{tabular}

energies $-11.1702,-14.1258$, and -13.77 , respectively, similar to the agonist serotonin which binds at the same site (Phe460, -19.1536).

Deacyl gymnemic acid, gymnemoside A, gymnemagenin, gymnema saponin III, and gymnema saponin I also show good binding energies similar or greater than the agonists.

\section{DISCUSSION}

Diabetes mellitus is considered to be a major public health concern throughout the world, including India. The metabolic abnormalities that characterize diabetes such as hyperglycemia, increased free fatty acids and insulin resistance, each provoke molecular mechanisms that contribute to vascular dysfunction. One of them is decreased bioavailability of NO. Deficiency of $\mathrm{NO}$ increases vascular resistance and promotes atherogenesis.

$\mathrm{NO}$ is produced from the amino acid L-arginine by the enzymatic action of eNOS. Under normal basal conditions

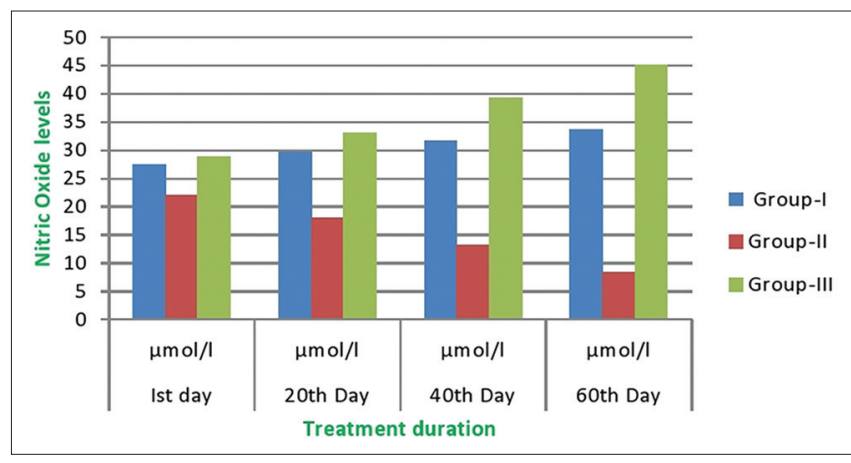

Figure 10: Nitric oxide levels after Gymnema sylvestsre extract administration

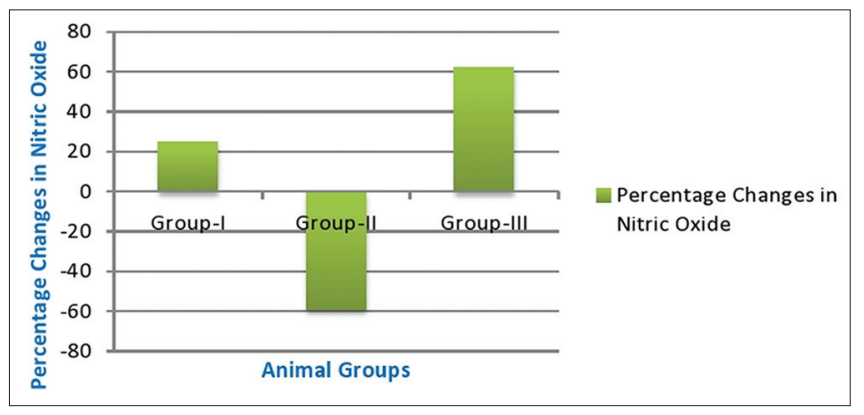

Figure 11: Percentage changes in nitric oxide after administration of Gymnema sylvestsre extract

in blood vessels, $\mathrm{NO}$ is continually being produced by eNOS. The bioavailability of NO reflects a balance between its production via NOS and its degradation, particularly by oxygen-derived free radicals. Agents such as acetylcholine, bradykinin, and serotonin act as agonists in the activation of the enzyme complex, NO synthase.

Since NO production is so important to avoid diabetic complications, the aim of the study was to find substances that may enhance the activity of eNOS enzyme and increase NO production.

GS has been used in ayurvedic medicine for the treatment of diabetes in India for centuries. When leaf extract of the plant, administered to a diabetic patient, there is stimulation of the pancreas by virtue of which there is an increase in insulin release. GS extract has also shown good antioxidant, free radical scavenging activity, and it is known to reduce the oxidative stress. ${ }^{18}$ Therefore, GS plant was selected to study its effect on enzyme eNOS.

The molecular docking approach can be used to model the interaction between a small molecule and protein at the atomic level, which allow us to characterize the behavior of small molecules in the binding site of target proteins as well as to elucidate fundamental biochemical processes. It helps identify the agonists and antagonists of the enzyme. Docking is widely used in rational drug design.

Journal of Young Pharmacists Vol 6 • Issue 4 • Oct-Dec 2014 
Table 5: NO levels after administration of GS extract

\begin{tabular}{lccccc}
\hline Groups & $\mathbf{1}^{\text {st }}$ day $(\boldsymbol{\mu m o l} / \mathbf{l})$ & $\mathbf{2 0}^{\text {th }}$ day $(\boldsymbol{\mu m o l} / \mathbf{l})$ & $\mathbf{4 0}^{\text {th }}$ day $(\boldsymbol{\mu m o l} / \mathbf{l})$ & $\mathbf{6 0}^{\text {th }}$ day $(\boldsymbol{\mu m o l} / \mathbf{l})$ & Percentage changes in NO \\
\hline I & $27.54 \pm 03.36$ & $29.69 \pm 3.32$ & $31.70 \pm 03.32$ & $33.75 \pm 03.10$ & $24.73 \pm 03.91$ \\
II & $21.97 \pm 03.84$ & $17.96 \pm 02.63$ & $13.23 \pm 01.69$ & $08.34 \pm 01.03$ & $\downarrow 58.96 \pm 04.96$ \\
III & $28.84 \pm 02.09$ & $33.13 \pm 03.31$ & $39.19 \pm 2.76$ & $45.15 \pm 0.052^{*}$ & $62.41 \pm 07.19$ \\
\hline *** Significant at $P<0.001 ;{ }^{* *}$ Significant at $P<0.01 ;{ }^{*}$ Significant at $P<0.05, \downarrow:$ Percentage decline in blood glucose, NO: Nitric oxide, GS: Gymnema sylvestsre
\end{tabular}

Hence, to study the effect of gymnema extract on enzyme eNOS molecular docking was performed. 10 compounds from the leaves of GS (gymnemic acid, gymnemasaponins I-V, gymnemagenin, gymnemosides $\mathrm{A}$ and $\mathrm{B}$, deacylgymnemic acid) were docked on the enzyme. It was observed that the binding energies for all the compounds were very low which shows that every compound has a good affinity for the enzyme eNOS.

The binding energies of these compounds were compared to the agonists' acetylcholine, bradykinin, and serotonin. Almost all the compounds bind to eNOS at the similar site as that of the agonist. These results prove that the gymnemasaponin and gymnemic acid might exert agonistic activity better than bradykinin and acetylcholine.

The results show that all the compounds from the leaves of GS might act as an agonist of eNOS. Further, to confirm the docking results animal studies were performed.

In Group I and III, GS extract was given orally at a dose of $400 \mathrm{mg} / \mathrm{kg}$ body weight every day up to 60 days. Blood glucose levels were monitored, and values were obtained.

In Group I, the blood glucose levels decreased after GS administration. In Group II (diabetic control), blood glucose levels increased significantly with the progression of the disease, whereas in Group III (treatment group), the levels decreased continuously from day 1 to $60^{\text {th }}$ day.

Student's $t$-test was done, and it was observed that decrease in blood glucose levels in Group I is slightly statistically significant $(P=0.045)$. But in Group III, which had diabetes, the decrease in blood glucose levels by GS extract was found to be extremely statistically significant $(P=0.001)$.

This result shows that GS extract effectively lowers the blood glucose levels in diabetic subjects and thus, can be used as a glucose-lowering agent in diabetics.

Serum NO levels were estimated spectrophotometrically using griess reagent. In diabetic rats (Group II), NO levels decreased. This may be due to glucose overload and inactivation of the enzyme eNOS. When the rats were treated with GS extract $(400 \mathrm{mg} / \mathrm{kg}$ ) until 60 days, a constant increase in the levels of $\mathrm{NO}$ was observed. In Group I, only received GS extract but no alloxan the NO levels increased.

Student's $t$-test shows that in Group I, the increase in NO levels was not statistically significant $(P=0.2849)$ but in Group III, the increase was very statistically significant $(P=0.0027)$.

The above data show that GS extract might help in increasing NO levels in diabetic patients and can help avoid diabetic vascular complications that occur as a result of decreased NO levels due to glucose overload and oxidative stress.

\section{CONCLUSION}

The docking study shows that almost every compound from leaves of GS can exert an agonist effect towards eNOS and promote NO synthesis. Animal studies also support the hypothesis with which the study was taken forward that the leaves of GS can help increase NO production by binding to eNOS and stimulating it. GS leaves can help in the future not only in controlling blood glucose levels in diabetics but might also help to avoid diabetic complications like vascular diseases that occur due to decreased availability of NO.

\section{REFERENCES}

1. Rother KI. Diabetes treatment - Bridging the divide. N Engl J Med. 2007;356:1499-501.

2. Turko IV, Marcondes S, Murad F. Diabetes-associated nitration of tyrosine and inactivation of succinyl-CoA: 3-oxoacid Co A-transferase. Am J Physiol Heart Circ Physiol. 2001;281:H2289-94.

3. Ogonowski AA, Kaesemeyer WH, Jin L, Ganapathy V, Leibach FH, Caldwell RW. Effects of NO donors and synthase agonists on endothelial cell uptake of L-Arg and superoxide production. Am J Physiol Cell Physiol. 2000;278:C136-43.

4. Altaha R, Fojo T, Reed E, Abraham J. Epothilones: A novel class of nontaxane microtubule-stabilizing agents. Curr Pharm Des. 2002;8:1707-12.

5. Kitchen DB, Decornez H, Furr JR, Bajorath J. Docking and scoring in virtual screening for drug discovery: Methods and applications. Nat Rev Drug Discov. 2004;3:935-49.

6. Sikarwar MS, Patil MB, Kokate CK, Sharma S, Bhat V. Antidiabetic activity of Nerium indicum leaf extract in alloxan-induced diabetic rats. J Young Pharm. 2009;1:340-5.

7. Al-Romaiyan A, Liu B, Asare-Anane H, Maity CR, Chatterjee SK, Koley N, et al. A novel Gymnema sylvestre extract stimulates insulin secretion from human islets in vivo and in vitro. Phytother Res. 2010;24:1370-6. 
8. Kumar G, Mishra PK, Prakash V. Antidiabetic and hypolipidemic activity of Gymnema sylvestre in alloxan induced diabetic rats. Glob J Biotechnol Biochem. 2009;4:37-42.

9. Altaha R, Fojo T, Reed E, Abraham J. Epothilones: A novel class of nontaxane microtubule-stabilizing agents. Curr Pharm Des. 2002;8:1707-12.

10. Heikkila RE. The prevention of alloxan-induced diabetes in mice by dimethyl sulfoxide. Eur J Pharmacol. 1977;44:191-3.

11. Ghosh MN. Fundamentals of Experimental Pharmacology. Vol. 2. Kolkata: Scientific Book Agency; 1984. p. 15-6.

12. Miles AM, Wink DA, Cook JC, Grisham MB. Determination of nitric oxide using fluorescence spectroscopy. Methods Enzymol. 1996; 268: 105-20.

13. Wagner KH, Elmadfa I. Biological relevance of gymnemins-overview focusing on acids. Ann Nutr Metab. 2003;47:95-106.
14. Kuroda C, Suzuki H. Synthesis of odd-membered rings by the reaction of beta-carbonylallylsilane or its derivative as a carbon 1, 3-dipole. Curr Org Chem. 2003;7:115-31.

15. Ridley RG. Medical need, scientific opportunity and the drive for antimalarial drugs. Nature. 2002;415:686-93.

16. Abdin MZ, Israr M, Rehman RU, Jain SK. Artemisinin, a novel antimalarial drug: Biochemical and molecular approaches for enhanced production. Planta Med. 2003;69:289-99.

17. Abebe W. Herbal medication: Potential for adverse interactions with analgesic drugs. J Clin Pharm Ther. 2002;27:391-401.

18. Kang MH, Lee MS, Choi MK, Min KS, Shibamoto T. Hypoglycemic activity of Gymnema sylvestre extracts on oxidative stress and antioxidant status in diabetic rats. J Agric Food Chem. 2012;60:2517-24. 